\title{
Selection of Probabilistic Model of Extreme Floods in Benue River Basin, Nigeria
}

\author{
Itolima Ologhadien
}

\begin{abstract}
The selection of optimum probabilistic model of extreme floods as a crucial step for flood frequency analysis has remained a formidable challenge for the scientific and engineering communities to address. Presently, there is no scientific consensus about the choice of probability distribution model that would accurately simulate flood discharges at a particular location or region. In practice, several probability distributions are evaluated, and the optimum distribution is then used to establish the design quantile - probability relationship. This paper presents the evaluation of five probability distributions models; Gumbel (EV1), 2-parameter lognormal (LN2), log Pearson type III (LP3), Pearson type III(PR3), and Generalized Extreme Value (GEV) using the method of moments (MoM) for parameter estimation and annual maximum series of four hydrological stations in Benue River Basin in Nigeria. Additionally, Q-Q plots were used to compliment the selection process. The choice of optimum probability distribution model was based on five statistical goodness - of - fit measures; modified index of agreement (Dmod), relative root mean square error (RRMSE), Nash Sutcliffe efficiency (NSE), Percent bias (PBIAS), ratio of RMSE and standard deviation of the measurement (RSR). Goodness - of - fit assessment reveals that GEV is the best - fit distribution, seconded by PR3 and thirdly, LP3. In comparison with WMO (1989) survey of countries on distribution types currently in use for frequency analysis of extremes of floods shows that GEV is standard in one country, while PR3 is a standard in 7 countries, and LP3 is standard in 7 countries. It is recommended that GEV, PR3 and LP3 should be considered in the final selection of optimum probability distribution model in Nigeria.
\end{abstract}

Index Terms - probability distribution model, optimum, floods, Benue River Basin, goodness - of - fit.

\section{INTRODUCTION}

Accurate estimates of the magnitudes and frequency of flood flows are needed for the design and operation of water -control infrastructure, floodplain demarcation and management, and for the design of transportation infrastructure such as bridges and roads, OPW [1]. The accuracy of quantile estimates depends on the choice of distribution, estimator and sample size, Anderson [2]. The steps in flood frequency analysis are:

i) selection of data series type;

ii) data screening;

iii) choice of parameter estimation method;

iv) assessment of uncertainties associated with the parameters and quantiles;

v) goodness - of -fit tests.

Published on January 5, 2021.

Itolima Ologhadien, Department of Civil Engineering, Rivers State University of Science and Technology, Nigeria.

(e-mail: itolima2000@yahoo.com)
The two main basic types of data series that can be extracted from hydrological records are (a) annual maximum series (AMS) and (b) partial - duration series, sometimes called the peaks -over threshold (POT) series. In the AMS, the largest flood event of each year is selected. The AMS is adopted because, it is consistent with the occurrence of floods in Benue River Basin, wherein, one damaging flood event occurs every year, EM 1110-21450 [3] and Khaliq [4]. In performing flood frequency analysis, the assumptions of data independence, adequacy, stationarity, and reliability must be verified, otherwise the resultant distributions may be significantly biased, leading to inappropriate designs with concomitant loss of property, ecosystems, and human life WMO168 [5].

A fundamental step in flood frequency analysis is the selection of an appropriate probability distribution model that can accurately simulate the observed flood series. Several probability distribution models have been considered in different situations, for the probabilistic modelling of extreme events, such as Generalized Extreme Value (GEV), Lognormal (2 and 3), Gamma (Gam), Gumbel Extreme Value type 1 (EV1), Log-Pearson Type 3(LP3), Pearson Type 3 (PR3). Some of the pertinent literature reviewed include Onoz [6], Chen [7], Vogel [8], Laio [9], Ahmad [10], Rahman [11], Morlot [12], Strupezewski [13], Prieto [14], Kousar [15], Hassan [16] and Philip [17]. Cannane [18] presented the state-of-the-art review of current practice with regard to use of distribution types for frequency analyses on extremes of precipitation and floods. The Review reported six most frequently used distribution type for flood frequency analysis in the following order of popularity: EV1, LP3, LN2, P3, GEV and Gamma. Furthermore, Cunnane [18] revealed that EV1, LN2, P3, and LP3 are most widely used distributions while one country used the GEV distribution in spite of its recent popularity. Consequently, for flood frequency analysis to be of practical use, commonly used distributions will be evaluated to establish the best - fit distribution. Rahman [11] studied the selection of probability distribution for atsite flood frequency analysis in Australia and identified LP3, GEV and generalized pareto-distribution (GPO) as the top three best-fit distributions. Onoz [6] evaluated various statistical distributions for determination of best-fit probability distribution from 19 stations all over the world and found GEV distribution superior to other six distributions examined. Vogel [8] studied the probability distribution of annual maximum, mean, and minimum stream flows in the United States. They found GEV, three parameters lognormal (LN3) and LP3 distributions good approximations to the distribution of annual maximum series. FLOODFREQ cost ES0901 [19] undertook a panEuropean comparison and evaluation of methods of flood 
frequency estimation and found no standardized European flood frequency estimation approach. And found that in a number of countries (i.e., Australia, Germany, Italy and Spain), GEV distribution is among the recommended choices, and a variety of 2- or 3- parameter distributions. Abida [20] studied regional flood frequency distributions for different zones in Tunisia and found the GEV and GLO superior to the other candidate distributions. Previous flood frequency studies conducted in the Benue River Basin worthy of mention are Izinyon [21], who found LN2, LP3 and EV1 the best-fit distributions for the Basin. To the best of my knowledge, and literature search, there was no prior study on the hydrological stations being evaluated; namely Benue River at Umaisha, Makurdi, Ibi, and Yola.

The well - known parameter estimation methods in civil engineering practice for probability distribution functions Rao [22] and VAN GELDER [23] are: (i) Methods of Moments (MoM), (ii) The Maximum Likelihood Method (MLM), (iii) The Probability Weighted Moments Method (PWM) and method of $\mathrm{L}-$ moments. A review of relevant literature on parameter estimation methods revealed some general guidelines by Hansen [24] and AMEC [25] revealed that PWM or L- moments is preferred to other estimators while MLE are not recommended for small sample sizes (less than 25). Furthermore, MLE is generally best for fitting LN2 for sample sizes longer than 25 years. Also, MoM performs best for Log - normal distributions with low skewness coefficient. Similarly, LP3 applies to hydrologic frequency analysis only when $\lambda$ (shape) $>1.0$ and $1 /$ (scale factor) $>0.0$ by Kite [26]. Sankarasubramanian [27] and Bezak [28] reported that the MoM was more suitable for data with lower skewness values and small sample sizes, whereas the method of L-moments was more suitable for data with higher skewness values and is appropriate for all sample sizes. In this study, MoM is used because of its simplicity and being relatively easy to apply by equating the sample moments with the moments of the population distribution functions.

The selection of candidate distribution is most commonly based on goodness - of- fit measures classified as (i) graphical assessments, (ii) statistical goodness -of - fit tests, (iii) hypothesis-based goodness -of - fit tests, and (iv) information -based criteria. The commonly used statistical indices are: (i) Relative Root Mean Square error (RRMSE), (ii) Nash - Sutcliffe efficiency (NSE), (iii) Percent bias (PBIAS), (vi) ratio of the root mean square error to the standard deviation of measured data (RSR) [29], [30] and [31]. In the hypothesis family are: i) Kolmogorov-Smirnov (KS) tests, ii) Anderson- Darling (AD) test, iii) Probability Plot Correlation and Coefficient (PPCC) tests, iv) Chisquared test, and v) log-likelihood ratio (t-test and f-test). Information-based criteria including the Akaike Information criterion, Akaike Information Criterion-second order variant (AICc) and Bayesian Information Criterion (BIC). Each method has its strengths and weaknesses when applied to model selection. Therefore, the selection of the best efficiency measures should reflect the intended use of the model and should concern model quantities which are deemed relevant for the study at hand Janssen [31]. Bennett [32] recommended calculating statistical goodness - of - fit for quantitative evaluation of the differences between observed and simulated discharges.

There is no established probability distribution model for accurate prediction of flood quantiles in Nigeria, while the country continues to suffer from devastating floods. For example, the 2012 "killer flood" caused 363 fatalities, displaced 7.7 million people, and approximately 600,000 houses were damaged. The "killer flood" amongst other consequences, worsened the existing housing deficit, thus placing huge pressure on all levels of governments to address the sharp increase in infrastructural demand by [33] and [34]. The objective of this paper is to evaluate the performances of five commonly used probability distribution models to find the best - fit distribution(s) that could be adopted in practice to represents the statistical characteristics or model the observed flood data in the Benue River Basin. The introductory section presents a literature review and background information on flood frequency analysis, together with a statement of the problem. Section 2 provides a synthesis of the methodology comprising the probability distribution functions used, parameter estimation method, goodness -of - fit tests, and procedure for estimation of flood quantiles and confidential interval. The study area, brief description of Benue River basin and data description are presented in section 3 . Section 4 contains results and discussion comprising derived flood quantiles, results of goodness - of - fit tests. The conclusion derived in this study and recommendations are presented in section 5 . The results of this study will be useful in water resources management and design of infrastructure to control the devastating impacts of floods.

\section{Methodology}

\section{A. Probability Distribution Functions}

A total of five probability distributions are considered for the comparative evaluation study. Two of these are two parameter distributions: EVI and LN2 and three, threeparameter distributions: LP3, PR3 and GEV. These distributions are the most frequently used or recommended frequency distribution types for extremes of both precipitation and floods by Cunnane [18], and Onoz [6]. Table 1 shows the probability distribution models, sample parameters and quantile estimators of the five distributors used in this study. Detailed procedures for flood frequency analysis may be found in Rao [22] and Naghettini [35].

\section{B. Selection of Parameter Estimation Method}

In the MoM approach, the parameters of the population probability model are estimated by the MoM by equating the sample moments with the moments of population probability model. The $\gamma^{\text {th }}$ moment of a probability distribution model $f(Q)$, about the origin is given by Rao [22]:

$$
\mu_{r}^{1}=\int_{-\infty}^{\infty} Q^{1} f(Q) d Q
$$

where $\mu_{r}^{1}=\mu=$ mean. 
The central moments $\mu_{r}$ are computed by:

$$
\mu_{r}=\int_{-\infty}^{\infty}\left(Q-\mu_{r}^{1}\right)^{r} f(Q) d Q, \mu_{1}=0,
$$

The sample moments $m_{r}^{1}$ and $m_{r}$ are calculated as:

$$
\begin{gathered}
m_{r}^{1}=\frac{1}{n} \sum_{i=1}^{n} Q_{i}^{r} ; m_{r}^{1}=\bar{Q} \\
m_{r}=\frac{1}{n} \sum_{i=1}^{n}\left(Q_{i}^{r}-\bar{Q}\right)^{r} ; m_{1}=0
\end{gathered}
$$

For correction of sample moments for bias, the conventional moment ratios given in Cunnane [18] and Rao [22] are defined as:

i) Coefficient of Variation:

$$
\mathrm{C}_{\mathrm{V}}=\mu_{2}^{1 / 2} / \mu_{1}^{1}
$$

ii) Coefficient of Skewness:

$$
\mathrm{C}_{\mathrm{C}}=\mu_{3} / \mu_{2}^{3 / 2}
$$

iii) Coefficient of Kurtosis:

$$
\mathrm{C}_{\mathrm{K}}=\mu_{4} / \mu_{2}^{2}
$$

\section{Goodness-of-fit-tests}

The goodness-of-fit assessment provides an objective assessment of the "closeness" between the simulated discharges $\left(\mathrm{Q}_{\text {sim }}\right)$ and observed measurements $\left(\mathrm{Q}_{\text {obs }}\right)$. The goodness - of -fit measures are selected to give sound comparative evaluation study with quantities deemed relevant to objective estimates of the "closeness" of the simulated discharges to observed flood flow Krause [36].

\section{Nash-Sutcliffe efficiency (NSE)}

NSE is a normalized statistic that determines the relative magnitude of the residual variance (information) Son [29], and Moriasi [30]). NSE ranges between $-\infty$ and 1.0 (1 inclusive), with NSE $=1$ being the optimal value.

$$
E=1-\left[\frac{\sum_{i=1}^{n}\left(Q_{i, o b s}-Q_{i, s i m}\right)^{2}}{\sum_{i=1}^{n}\left(Q_{i, o b s}-Q_{o b s}\right)^{2}}\right]
$$

\section{RMSE - Observation Standard Deviation Ratio (RSR)}

RMSE - observations standard deviation ratio (RSR), standardized RMSE using observation standard deviation, and combines both an error index and additional information. RSR is calculated as the ratio of the RMSE and standard deviation of the measured data. RSR varies from optimal value of 0 , which indicates zero RMSE or residual variation and therefore a perfect model simulation, to a large positive value. The lower RSR, the lower the RMSE, and the better model simulation performance Son [29]. RSR is calculated as shown in Equation 9:

$$
R S R=\frac{R M S E}{S T D E V_{o b s}}=\frac{\left[\sqrt{\sum_{i=1}^{n}\left(Q_{i . o b s}-Q_{i, s i m}\right)^{2}}\right]}{\sqrt{\sum_{i=1}^{n}\left(Q_{i . o b s}-\bar{Q}_{\text {sim }}\right)^{2}}}
$$

\section{Modified Index of Agreement (Dmod)}

Dmod is formulated based upon sum of the absolute values of the errors and is less sensitive to errors concentrated in outliers compared to previous version of the index. The advantage of Dmod over Index of Agreement and coefficient of determination $\left(\mathrm{R}^{2}\right)$ is that it approaches 1.0 more slowly as $\mathrm{Q}_{\text {obs }}$ approaches $\mathrm{Q}_{\text {sim }}$ and therefore provides greater separation when comparing models that perform relatively well. The modified Index of Agreement (Dmod) is:

$$
D \bmod =1-\frac{\sum_{i=1}^{n}\left\|\left(Q_{s i m, i}-Q_{o b s, i}\right)\right\|}{\sum_{i=1}^{n}\left(\left\|Q_{s i m, i}-\bar{Q}_{o b s,}\right\|+\left\|Q_{o b s, i}-\bar{Q}_{o b s,}\right\|\right)}
$$

where $Q_{\text {sim }}$, is simulated discharges, $Q_{o b s}$, is observed discharge, and $\bar{Q}_{o b s, i}$ is mean value of observed discharges. Furthermore, Dmod is less sensitive to the shape of the error-frequency distribution, and consequently, to error concentrated in outliers by Willmott [37].

\section{Relative-Root-Mean-Square Error (RRMSE)}

The RRMS statistics is formulated based on the relative errors between observed and simulated discharges. The simulation error is calculated in proportion to the size of the observations, thus reducing the influence of outliers and providing better picture of the overall fit of a distribution than RMSE Tao [38].

$$
R R M S=\left[\frac{1}{n-m} \sum_{i=1}^{n}\left(\frac{Q_{o b s, i}-Q_{s i m, i}}{Q_{o b s, i}}\right) 2\right]^{\frac{1}{2}}
$$

\section{Percent Bias (PBIAS)}

Percent bias (PBIAS) measures the average tendency of the simulated data to be larger or smaller than their observation counterparts. The optimal value of PBIAS is 0.0 , with low-magnitude values indicating accurate model simulation. Positive values indicate model underestimation bias, and negative values indicate model overestimation bias by [39] and [29].

PBIAS $=\left[\frac{\sum_{i=1}^{n}\left(Q_{i . o b s}-Q_{i, \text { sim }}\right)^{2} * 100}{\sqrt{\sum_{i=1}^{n}\left(Q_{i . o b s}\right)}}\right]$ 
TABLE 1: Probability MOdels, SAMPle PARAMETERS AND MOMENTS

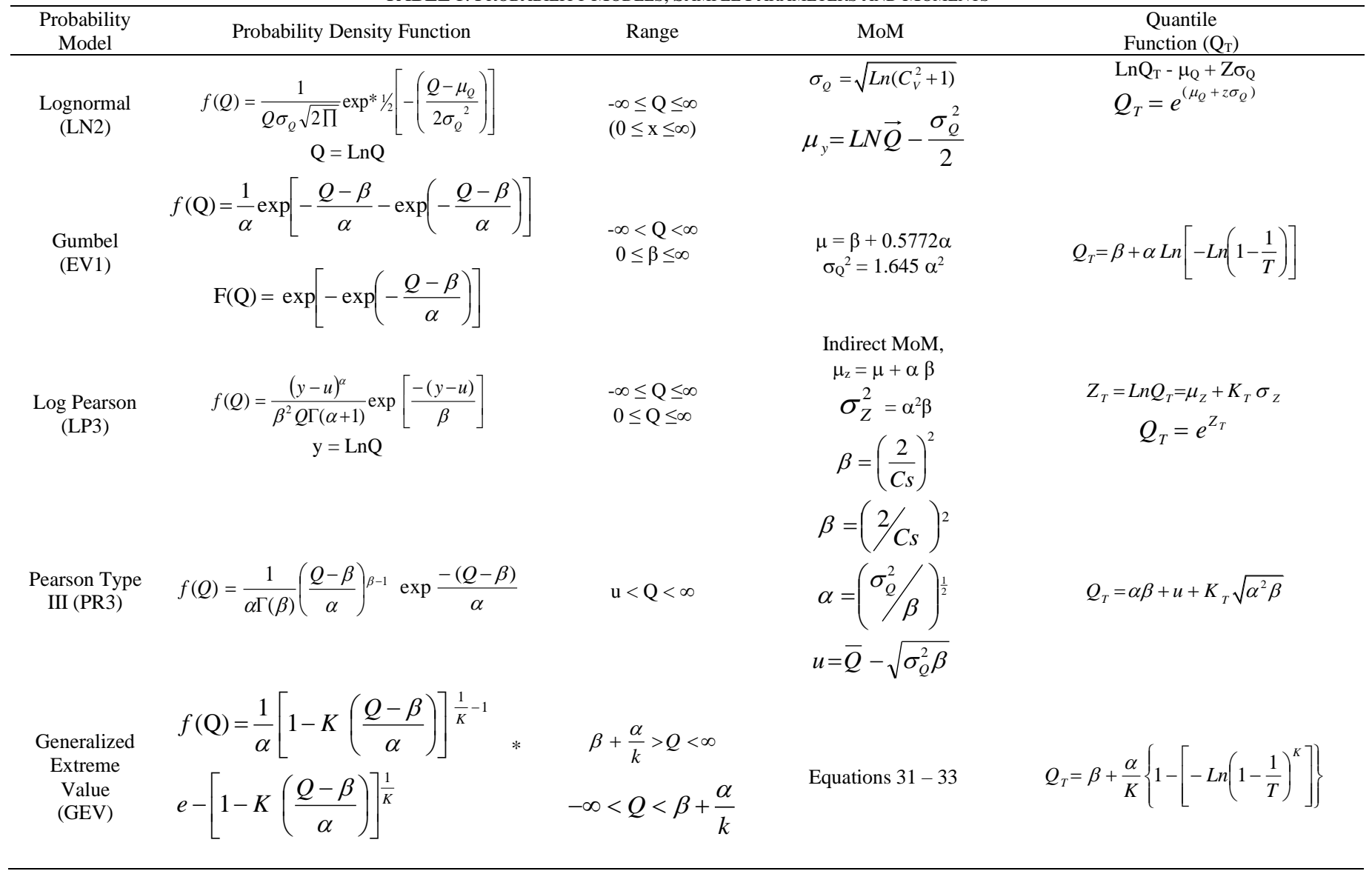

Where $\beta, \alpha$ and $\mathrm{k}$ are the location, scale, and shape parameters of the distribution.

\section{Quantile-Quantile $(Q-Q)$ plots}

The $\mathrm{Q}-\mathrm{Q}$ plot is a graph of the dataset arranged in ascending order and then plotted against the expected value for the specified distribution at each quantile in the sample datasets. The plot displays the sample of quantiles $\mathrm{s} 1, \ldots \mathrm{sn}$ against distribution quantiles $\mathrm{F}^{-1}(\mathrm{Pi}), \ldots, \mathrm{F}^{-1}(\mathrm{Pn})$, where $\mathrm{Pi}$ is plotting position formula, Pandit [40]. The points may be defined as:

$$
f\left(x_{i}, y_{i}\right)=\left(F^{-1}(P), G^{-1}(P)\right) \text { for } 0<P<1
$$

The unbiased plotting position formulas have the general formula, Cunnane [41]:

$$
\mathrm{Pi}=\frac{i-a}{n+1-2 a}
$$

where "a" varies from 0 to 0.5 ; $\mathrm{Pi}$ is the plotting probability and $i$ is the rank in ordered observation with $i=1$ for the smallest observation in data sample. In Equation 14; when a $=0.375$; Blom formula was used for LN2 distribution, when $\mathrm{a}=0.44$, Gringorten formula was used for Gumbel (EVI) distribution; for $\mathrm{a}=0.4$, Cunnane formula was used for LP3 and GEV distributions. The unbiased plotting formula for PR3 (IN-NA [42] and WMO: No.718 [43]) was used.

$$
\mathrm{P}=(\mathrm{i}-0.53+0.3 \mathrm{Cs}) /(\mathrm{N}+0.05+0.3 \mathrm{Cs}),
$$

where Cs is coefficient of skewness, $\mathrm{N}$ is sample size and $\mathrm{i}$ is rank with $i=1$ indicating the smallest sample number.

\section{Procedure for Estimation of Flood Quantiles}

The procedure for estimation of flood quantiles for the selected probability distribution models are presented below:

\section{Gumbel's Extreme - Value Type 1 (EVI)}

Gumbel (EV1) distribution may be used to model a variety of phenomena involving extreme events. EV1 is adopted as standard probability distribution model of flood flow in sixteen countries. The EV1 distribution uses two parameters location $(\mu)$ and scale $(\alpha)$. The procedure for computing the T-year recurrence interval are:

i) Compute the sample moments: mean $(\bar{Q})$ and variance $\left(\sigma_{Q}^{2}\right)$.

ii) Compute the MoM estimators/estimates by solving for $\alpha$ and $\beta$ from equations 15 and 16 respectively:

$$
\begin{aligned}
& \alpha=0.7797 \sigma_{Q} \\
& \beta=\bar{Q}-0.45005 \sigma_{Q}
\end{aligned}
$$

iii) Calculate the $\mathrm{T}$-year quantile by subtracting $F=\left(1-\frac{1}{T}\right)$ where $\mathrm{T}$ is the return period.

iv) Compute the EV1 reduced variate $\left(\mathrm{y}_{\mathrm{T}}\right)$ :

$$
y_{T}=-L N\left[-L N\left(\frac{T-1}{T}\right)\right]
$$

v) Compute the inverse function, or quantile function for the Gumble (EV1). 
$\mathrm{Q}_{\mathrm{T}}=\beta+\alpha \mathrm{yT}$

$$
\begin{aligned}
& \text { Or } \\
& \mathrm{Q}_{\mathrm{T}}=\beta+\alpha \mathrm{LN}^{*}\left[-L N\left(1-\frac{1}{T}\right)\right]
\end{aligned}
$$

\section{Log-Normal Distribution (Ln2)}

The log-normal distribution occurs in practice when a random variable $(\mathrm{Q})$ which is such that its logarithm follows normal distribution. In case the logarithms of a random variable $(\mathrm{Q})$ are not normally distributed, a boundary parameter $(\mu)$ is introduced before taking logarithms will solve the problem, thus yielding a 3parameter log-normal distribution (LN3), Stedinger [44]. The steps needed to compute the discharge $\mathrm{Q}_{\mathrm{T}}$ of return period (T) are as follows:

i) Logarithmic transformation of all discharge values to base e.

ii) Compute the mean $(\bar{Q})$, and the variance $\left(\sigma_{Q}^{2}\right)$ from the logarithmic series.

iii) Compute MoM estimators/estimates for $\sigma_{Q}^{2}$ and $\mu_{Q}$ from their respective samples estimates: $(\bar{Q})$ and variance.

iv) Compute the probability of non-exceedance as:

$$
p_{i}=1-\frac{1}{T}
$$
$\mathrm{P}_{\mathrm{i} .}$

v) Calculate the standard normal variate corresponding to

vi) Calculate the frequency factor $\left(\mathrm{K}_{\mathrm{T}}\right)$ for Log-normal as in step (v); (i) and (ii) for LP3.

vii) Calculate the quantile estimate as:

$$
\begin{aligned}
\mathrm{LNQ}_{\mathrm{T}} & =\mu_{Q}+\mathrm{K}_{\mathrm{T}} \sigma_{Q} \\
\therefore \mathrm{Q}_{\mathrm{T}} & =e^{\left(\mu_{Q}+K_{T} \sigma_{Q}\right)}
\end{aligned}
$$

\section{Log Pearson Type III (Lp3)}

The LP3 is a member of Gamma distribution family. It uses 3 parameters: location $(\mu)$, scale $(\alpha)$ and shape $(\beta)$. If the logarithm of a variable (LNQ) obeys Pearson Type III distribution, then $\mathrm{Q}$ can be described according to the log. Pearson Type III (LP3) distribution see Rao [22] and Naghavi [45]. The steps using MoM estimators to compute $\mathrm{Q}_{\mathrm{T}}$ are:

i) Transform the Annual Maximum Series AMS) to $\mathrm{LNQ}_{1}, \mathrm{LNQ}_{2}, \ldots \ldots, \mathrm{LNQ}_{\mathrm{n}}$.

ii) Compute the mean $(\bar{Q})$, variance $\left(\sigma_{Q}^{2}\right)$ and skew $(\mathrm{Cs})$ of the log-transformed series.

iii) Estimation of LP3 distribution parameters ( $\alpha \beta$ and $\mathrm{u}$ ) by the Method of Moment; the sample moments (mean standard deviation and skew coefficient).

iv) Determine the MoM estimators: LP3 ( $\alpha, \beta$ and $u)$.

v) Calculate the frequency factor $K_{T}$ is calculated as follows:

$$
W=\left[L N\left(\frac{1}{P^{2}}\right)\right]^{1 / 2}
$$

$$
z=w-\frac{2.515517+0.802853 w+0.010328 w^{2}}{1+1.432788 w+0.189269 w^{2}+0.001308 w^{3}}
$$

when $p>0.5,1-p$ is substituted for $p$ in equation 23 and the value of $\mathrm{z}$ computed by equation 23 is given a negative sign.

$\mathrm{K}_{\mathrm{T}}$ is approximated by Kite [26] as:

$$
\mathrm{K}_{\mathrm{T}}=\mathrm{z}+\left(\mathrm{z}^{2}-1\right) \mathrm{k}+\frac{1}{3}\left(z^{3}-6 z\right) k^{2}-\left(z^{2}-1\right) k^{3}+z k^{4}+\frac{1}{3} k^{5}
$$

where $\mathrm{k}=\mathrm{Cs} / 6$.

vi) The T-year flood quantile is obtained by Equations 25 and 26

$$
\begin{aligned}
& \mathrm{Z}_{\mathrm{T}}=\mathrm{LNQ}_{\mathrm{T}}=\mu_{\mathrm{z}}+\mathrm{K}_{\mathrm{T}} \sigma_{\mathrm{z}} \\
& \mathrm{Q}_{\mathrm{T}}=\mathrm{e}^{\mathrm{ZT}}
\end{aligned}
$$

\section{Pearson Type III: Distribution}

Pearson Type III (PR3) has been adopted as the standard method for flood frequency analysis in seven countries. PTIII is a three parameter distribution $(\alpha, \beta$ and $u)$, therefore, three sample moments (mean $(\mu)$, variance $\left(\sigma_{\mathrm{y}}{ }^{2}\right)$, and skewness are required, from the sample data to compute the population parameters. The sample moments $(\mathrm{E}(\mathrm{Q}), \operatorname{var}(\mathrm{Q})$ and $\mathrm{Cs}$ are estimated from their relations to the distribution parameters, which in turn, are estimated by MoM. The following steps may be followed in computing the T-year flood using the PT-III distribution:

i) Calculate the sample moments (mean, variance and skew).

ii) Compute the standard normal variate (u)

corresponding to a probability of non-exceedance, $\mathrm{P}=1-1 / \mathrm{T}$. iii) Compute the frequency factor from the following approximation by Wilson [46]:

$K_{T}=\frac{2}{C s}\left[\left\{\frac{C s}{6}\left(\mu-\frac{C s}{6}\right)+1\right\}^{3}-1\right]$ for $0 \leq \mathrm{Cs} \leq 1.0$ and up

to 2.0

iv) Abramawitz [47] gave the value of $u$ as:

$$
u=W-\frac{C o+C_{1} W+C_{2} W^{2}}{1+d_{1} W+d_{2} W^{2}+d_{3} W^{3}}+E(P)
$$

where

$$
\begin{gathered}
\mathrm{C}_{0}=2.515517 ; \mathrm{C}_{1}=0.802853 ; \mathrm{C}_{2}=0.010328 ; \\
\mathrm{d}_{1}=1.432788, \mathrm{~d}_{2}=0.189269, \mathrm{~d}_{3}=0.001308 .
\end{gathered}
$$

$$
\mathrm{W}=\sqrt{-2 \log (p)} \text { for } P<0.5
$$

where $\mathrm{P}=1-\mathrm{F}$, the probability of exceedance, and the error $\varepsilon(\mathrm{P})$ is less than $4.5 \times 10^{-4}$.

For $\mathrm{P}>0.5, \mathrm{P}$ is replaced by $1-\mathrm{P}$ and the required " $\mathrm{u}$ " is the computed "u" but with an opposite sign.

v) The skewness coefficient Cs in Equation 27 is given by: 


$$
C s=\frac{\alpha}{\|\alpha\|} \times \frac{2}{\sqrt{\beta}}
$$

vi) The quantile $\mathrm{Q}_{\mathrm{T}}$ for $\mathrm{P}_{\mathrm{T}}-\mathrm{III}$ is given:

$$
Q_{T}=\alpha+\beta+u+K * \sqrt{\wedge \alpha^{2}+\beta}
$$

where:

$$
\begin{aligned}
& \beta=\left(\frac{2}{C s}\right)^{2} \text { and Cs is sample estimate. } \\
& \alpha=\left(\frac{\operatorname{Var}[Q]}{\beta}\right)^{1 / 2} \\
& \mathrm{u}=\mathrm{E}(\mathrm{Q})-\sqrt{\operatorname{Var}[Q] \times \beta}
\end{aligned}
$$

\section{Generalized Extreme Value (GEV) Distribution}

The generalized extremes value (GEV) is a threeparameter distribution; shape $(\mathrm{k})$, location $(\mu)$, and scale $(\sigma)$. GEV distribution is a combination of three different distributions according to the shape parameter, when the $\mathrm{k}=0$, the GEV distribution reduces to Gumbel (EV1) distribution, when $\mathrm{K}<0$ ), we have Extreme Value type II (Fetchet), when K > 0, GEV becomes Extreme Value Type III.

The three parameters of the (GEV) distribution; shape (k), location (beta), and scale (a) may be estimated from the sample moments; mean (E(Q)), variance (Var [Q]), and skew coefficient (Cs) using Equations $31-33$ as follows:

$$
\begin{aligned}
& \alpha=\left(\frac{K^{2} \operatorname{Var}[Q]}{\Gamma(1+2 K)-\Gamma^{2}(1+K)}\right)^{1 / 2} \\
& \beta=E[Q]-\frac{\alpha}{K}[1-\Gamma(1+K)]
\end{aligned}
$$

The shape parameter $(\mathrm{k})$ is calculated from the skew coefficient (Cs) using the equation given by Rao [22] for -2 $<\mathrm{Cs}<1.1396(\mathrm{EV} 3)$.

$$
\begin{gathered}
\mathrm{K}=0.277648-0.32201 C s+0.060278 C_{s}^{2}+0.016759 C_{s}^{3}- \\
0.005873 C_{s}^{4}-0.00244 C_{s}^{5}-0.00005 C_{s}^{6}
\end{gathered}
$$

The following steps may be followed to compute the GEV quantiles:

i) Using the MS Excel built-in-functions compute the three first sample moments, namely, the mean E[Q], variance, Var [Q], and coefficient of skewness (Cs).

ii) Using the calculated coefficient of skewness (Cs), select the appropriate range of inequality, thus Equation 33 was selected based on the estimated shape parameter, $\mathrm{k}$ according to Rao [22].

iii) Estimate the other two MoM estimators: $\alpha$ and $\beta$ from Equations 31 and 32 respectively.

iv) Note the MoM estimates for $\operatorname{GEV}(\alpha, \beta$ and $\mathrm{k}$ ) followed the substitution of $\mathrm{Q}, \sigma_{Q}^{2}$ and $\mathrm{Cs}$ by their respective sample estimates. v) Compute the T-year quantile estimate by substituting $\mathrm{P}=1-1 / \mathrm{T}$, where $\mathrm{T}$ is the return period.

vi) Compute the $\mathrm{T}$-year quantile estimate as:

$$
\mathrm{Q}_{\mathrm{T}}=\beta+\frac{\alpha}{k}\left[1-\left\{-\ln \left(\frac{T-1}{T}\right)\right\}^{K}\right]
$$

\section{Uncertainty Assessment}

Uncertainty is approximated by the confidence interval of the estimated quantiles of the selected probability distributions at specified return periods. The confidence interval specifies the probability that the quantiles estimates lie within the upper and lower confidence interval coefficients; $\mathrm{K}^{\mathrm{U}} \mathrm{Tr}_{\beta}$ and $\mathrm{K}^{\mathrm{L}} \mathrm{Tr}, \beta$ using the non - central $\mathrm{t}$ distribution. Confidence limits are computed as follows:

$$
\begin{aligned}
& \mathrm{U}_{\operatorname{Tr}, \beta}(\mathrm{Q})=\bar{Q}+\mathrm{K}^{\mathrm{U}}{ }_{\operatorname{Tr}, \beta} \times \sigma \\
& \mathrm{L}_{\operatorname{Tr}, \beta}(\mathrm{Q})=\bar{Q}+\mathrm{K}^{\mathrm{L}}{ }_{\mathrm{Tr}, \beta} \times \sigma
\end{aligned}
$$

Where $\bar{Q}$, and $\sigma$ are the $\log$ base -10 mean and standard deviation, $\mathrm{U}_{\mathrm{Tr}, \beta}(\mathrm{Q})$ and $\mathrm{L}_{\mathrm{Tr}, \beta}(\mathrm{Q})$ are the upper and lower limits respectively. More details may be found in Rao [22], p200.

\section{STUDY AREA AND DATA DESCRIPTION}

The Benue River Basin is the major tributary of the River Niger forming a confluence at Lokoja and it contributes more than the actual Niger River discharges at the confluence. It originates from the Adamawa Plateau in Cameroun. The Benue River has a total length of $1200 \mathrm{~m}$ from origin to the confluence at Lokoja and about 4.4 percent $\left(66,000 \mathrm{~km}^{2}\right)$ of the Benue Basin lies in Cameroun, Golitzen [48]. Table 2 shows the geographical and background information of the four hydrological stations. The AMS of the four hydrological stations have data length of 30 years were used. Table 2 also contains the descriptive statistics of the flood data, showing the coefficient of variation (cv) ranged between 0.194 and 0.313 , which implies that the year-to-year variation of the AMS is moderately variable. The coefficient of skewness (cs) ranges between 0.301 and 0.575 , all positive values, which implies non - normal probability distribution. The AMS data for River Benue at Ibi, Umaisha, Makurdi and Yola gauging stations (Fig. 1) was obtained from the Nigerian Inland Waterways Authority (NIWA), Lokoja Nigeria. The NIWA authority operates the river gauging stations of the Lower River Basin in Nigeria. Furthermore, the fundamental requirement for randomness, independence, homogeneity, and stationarity were tested using the nonparametric tests of turning point, Wald-Wolfswitz, Mann Witney and Spearman Rho, and no empirical evidence was found to rule out the assumptions. 
TABLE 2: CHARACTERISTICS OF SELECTED HYDROLOGICAL STATIONS

\begin{tabular}{|c|c|c|c|c|c|c|c|c|}
\hline (1) & (2) & (3) & (4) & (5) & $(6)$ & (7) & $(8)$ & (9) \\
\hline $\mathrm{S} / \mathrm{N}$ & Stations & Latitude & Longitude & Catchment & \multicolumn{2}{|c|}{ Annual streamflow } & Coeff. of Variation & Skewness \\
\hline & & $(\mathrm{N})$ & $(\mathrm{E})$ & $\mathrm{Km}^{2}$ & $\operatorname{Max~} \mathrm{m}^{3} / \mathrm{s}$ & $\operatorname{Min} \mathrm{m}^{3} / \mathrm{s}$ & $(\mathrm{CV})$ & $\mathrm{Cs}$ \\
\hline 1 & Ibi & $08^{\circ} 11^{\prime}$ & $09^{\circ} 45^{\prime}$ & 275,370 & $12,454.94$ & 12.68 & 0.251 & 0.575 \\
\hline 2 & Makurdi & $07^{\circ} 45^{\prime}$ & $08^{\circ} 32^{\prime}$ & 317,430 & $16,034.93$ & 30.48 & 0.194 & 0.469 \\
\hline 3 & Umaisha & $08^{\circ} 00^{\prime}$ & $07^{\circ} 14^{\prime}$ & 343,210 & $18,408.97$ & 7.71 & 0.254 & 0.349 \\
\hline 4 & Yola & $09^{\circ} 14^{\prime}$ & $12^{\circ} 28^{\prime}$ & 112,680 & $6,641.30$ & 8.93 & 0.313 & 0.301 \\
\hline
\end{tabular}

Extracted from Hydrological Year Book (1914-1989): National Inland Waterways Authority, Lokoja, Nigeria.

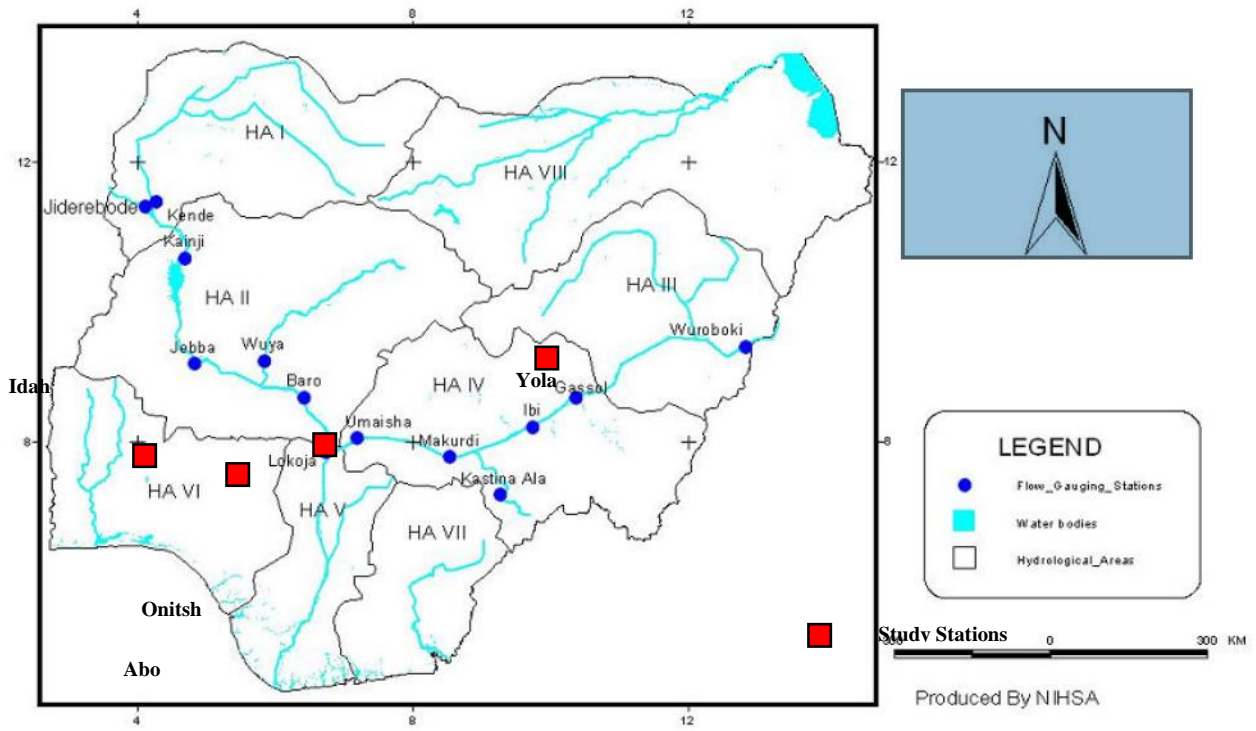

Fig. 1. Hydrological stations (in red squares). (Adapted from NIHSA, 2004).

Nigerian Hydrological Services Agency (NIHSA), 2014).

TABLE 3: DiSTRIBUTION PARAMETERS AND QUARTILE RELATIONS

\begin{tabular}{|c|c|c|c|c|c|}
\hline \multirow{2}{*}{ Station } & \multicolumn{4}{|c|}{ Distribution Parameters } & \multirow[b]{2}{*}{$Q_{T}-T$ Models } \\
\hline & PDF & $\beta$ & $\alpha$ & $K($ or $\gamma)$ & \\
\hline \multirow{6}{*}{ Umaisha } & & & & & $\mathrm{Q}_{\mathrm{T}}=8879.04+39 Y_{T}$ \\
\hline & $E V 1$ & 8879.041 & 1989.390 & - & $L_{n Q T}=9.18+39 K_{T}$ \\
\hline & $L N 2$ & 9.18 & 0.260 & - & $L_{n Q T}=9.18+0.259 K_{T}$ \\
\hline & $L P 3$ & 141.97 & 0.022 & 6.10 & $\mathrm{Q}_{\mathrm{T}}=10027.17+2551.48 K_{T}$ \\
\hline & $P R 3$ & 32.819 & 445.378 & -4589.79 & $\int\left[\tau^{2}(\tau-1)\right]^{0.173}$ \\
\hline & $G E V$ & 9007.563 & 13729.01 & 0.173 & $\mathrm{Q}_{\mathrm{T}}=9007.563+137291.81\left\{1--\ln \left(\frac{\tau-1}{\tau}\right)\right.$ \\
\hline \multirow{6}{*}{ Makurdi } & & & & & \multirow{4}{*}{$\begin{array}{c}\mathrm{Q}_{\mathrm{T}}=9197.077+1526.42 Y_{T} \\
L_{n Q T}=9.22+0.104 K_{T} \\
L_{n Q T}=9.20+193 K_{T} \\
\mathrm{Q}_{\mathrm{T}}=10078.01+1957.71 K_{T}\end{array}$} \\
\hline & $E V 1$ & 9197.077 & 1526.42 & - & \\
\hline & $L N 2$ & 9.20 & 0.193 & - & \\
\hline & $L P 3$ & 8853.63 & 0.0021 & -8.98 & \\
\hline & $P R 3$ & 18.31 & 457.48 & 1700.29 & $\left([-(\tau-1)]^{0.342}\right)$ \\
\hline & $G E V$ & 9273.04 & 1777.89 & 0.142 & $\mathrm{Q}_{\mathrm{T}}=9273.04+12545.67\left\{1--\ln \left(\frac{\tau-1}{\tau}\right)\right.$ \\
\hline \multirow{6}{*}{ Ibi } & & & & & \multirow{4}{*}{$\begin{array}{c}\mathrm{Q}_{\mathrm{T}}=7415.658+1657.34 Y_{T} \\
L_{n Q T}=9.0+0.25 K_{T} \\
L_{n Q T}=8.994+0.305 K_{T} \\
\mathrm{Q}_{\mathrm{T}}=8372.148+2125.616 K_{T}\end{array}$} \\
\hline & $E V 1$ & 7415.658 & 1657.342 & - & \\
\hline & $L N 2$ & 9.0 & 0.25 & - & \\
\hline & $L P 3$ & 1.67 & 0.236 & 8.60 & \\
\hline & $P R 3$ & 12.109 & 610.844 & 975.426 & \multirow{2}{*}{$\mathrm{Q}_{\mathrm{T}}=7826.864+4771.643\left\{1-\left[-\ln \left(\frac{\tau-1}{\tau}\right)\right]^{0.479}\right\}$} \\
\hline & $G E V$ & 7826.864 & 2285.596 & 0.479 & \\
\hline \multirow{6}{*}{ Yola } & & & & & $\mathrm{Q}_{\mathrm{T}}=2987.258+1111.283 Y_{T}$ \\
\hline & $E V 1$ & 2987.238 & 1111.29 & - & $L_{n Q T}=8.125+0.379 K_{T}$ \\
\hline & $L N 2$ & 8.125 & 0.379 & - & $L_{n Q T}=8.115+0.427 K_{T}$ \\
\hline & $L P 3$ & 18.337 & 0.0997 & 6.287 & $\mathrm{Q}_{\mathrm{T}}=3628.605+1425.273 K_{T}$ \\
\hline & $P R 3$ & 44.141 & 214.524 & -5840.754 & \multirow{2}{*}{$\mathrm{Q}_{\mathrm{T}}=3066.43+7192.97\left\{1-\left[-\ln \left(\frac{\tau-1}{\tau}\right)\right]^{0.187}\right\}$} \\
\hline & $G E V$ & 3066.43 & 1342.044 & 0.187 & \\
\hline
\end{tabular}

\section{RESUlts AND DisCUSSIONS}

\section{A. Results}

The estimated parameters for each distribution across the hydrological stations and the quantile relations expressed in the form of $\mathrm{Q}_{\mathrm{T}}-\mathrm{T}$ reationships are presented in Table 3. The quantile estimate $\mathrm{Q}_{\mathrm{T}}$ expressed in terms of the cumulative probability of non - exceedance $(1-1 / \mathrm{T})$.
The quantile relations for the probability models were derived via unbiased position formulas given in subsection C.6 using the cumulative probability of non - exceedance. The predictive performances of the probability distribution models were evaluated using the statistical performance evaluation criteria; Dmod, RRMSE, NSE, PBIAS, and RSR. These indices are recommended standardized guidelines for judging model performance and comparing 
various models, ASCE [49] and Son [29]. A ranking scheme was devised to rank the distributions based on their test values. Ranking scores are assigned to each distribution according to the optimal value of the statistical criteria. For example, the distribution with the lowest RRMSE, RSR or PBIAS values close to zero, and highest NSE, Dmod, and total accuracy of 1.0 is given a rank of 5. Accordingly, for each criterion, the overall ranks associated with each distribution is computed by summing the individual ranks obtained for each study station. The highest score implies the best - fit distribution. Using this ranking scheme, it was plausible to find the best distribution for each station Son [29].

Fig. 2-6, show that all the probability distribution models gave good system response dynamics for the observed flood discharges. Figure 6 shows that the GEV predicted hydrographs simulates better the observed hydrograph, wherein both hydrographs (observed and simulates) match each other better. Similarly, Fig. 7-11 show that the Q-Q plots generally indicate good agreement between the theoretical line and the simulated values for all distributions, however the agreement is better with GEV than for other distributions. Due to lack space, the plots for other study stations are not displayed.

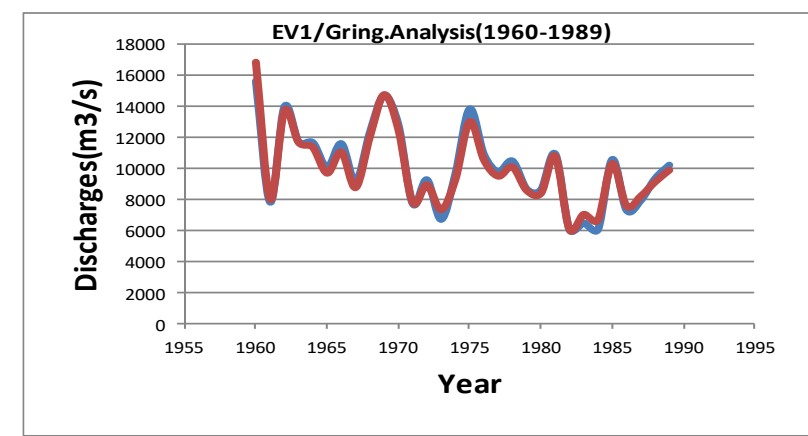

Fig. 2. Observed and Simulated Discharges (Umaisha).

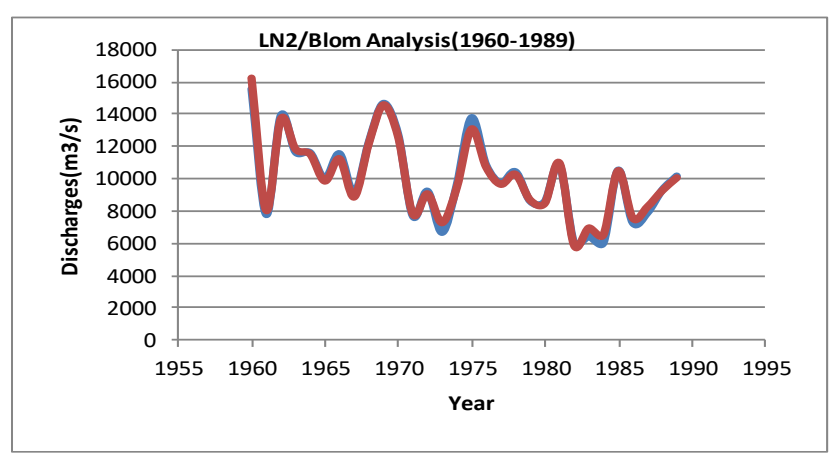

Fig. 3. Observed and Simulated Discharges (Umaisha).

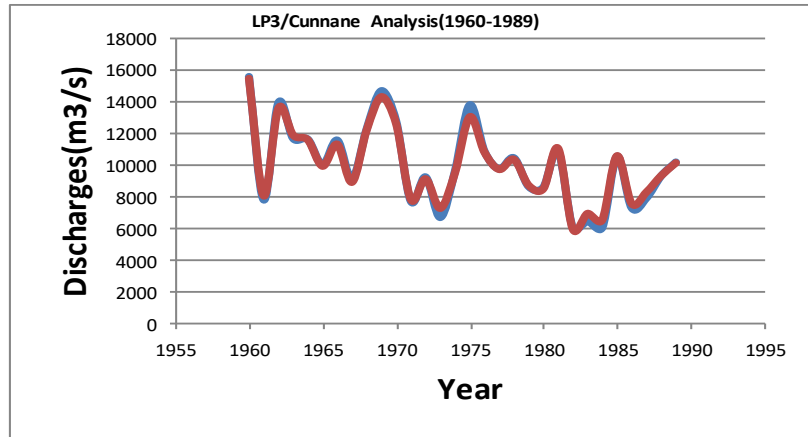

Fig. 4. Observed and Simulated Discharges (Umaisha).

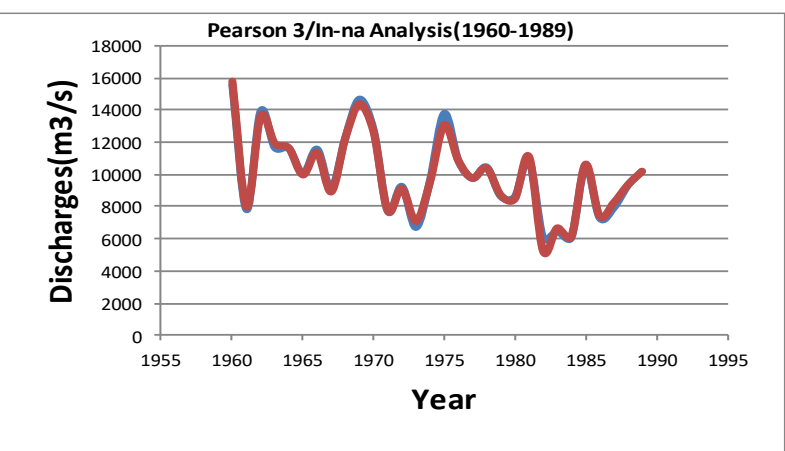

Fig. 5. Observed and Simulated Discharges (Umaisha).

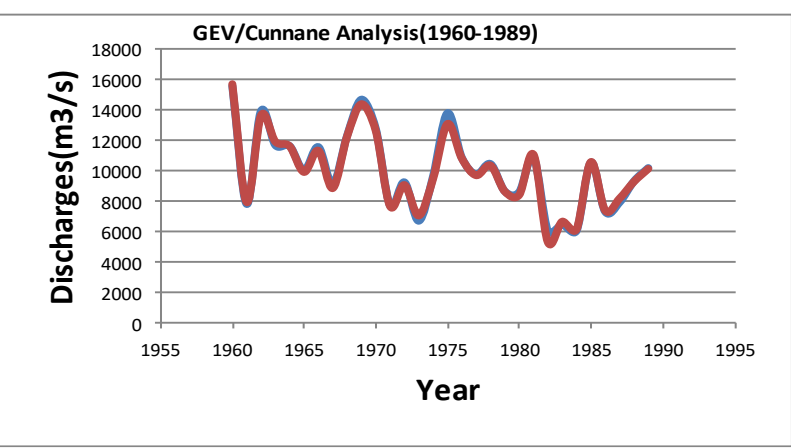

Fig. 6. Observed and Simulated Discharges (Umaisha).

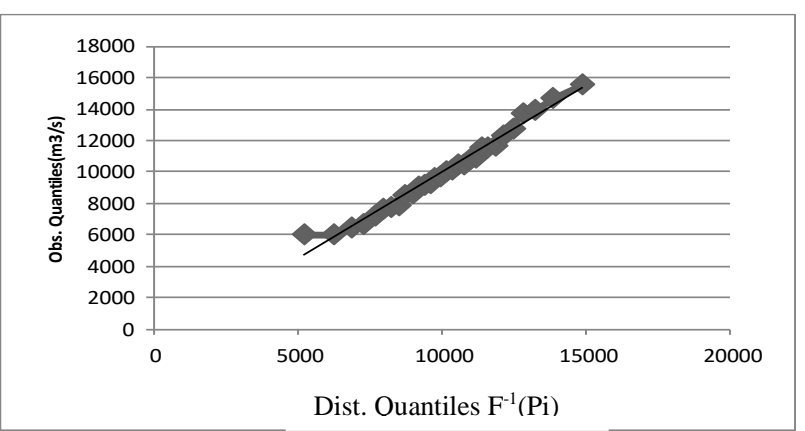

Fig. 7. EV1 Q-Q Plot for Flood Flow Umaisha.

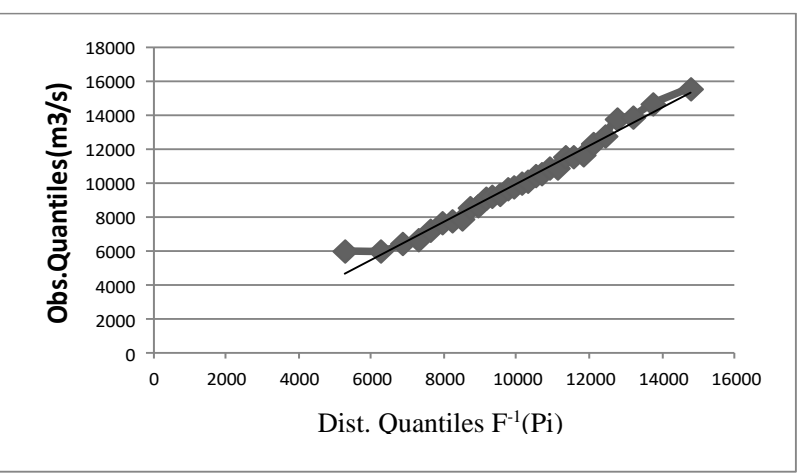

Fig. 8: LN2 Q-Q Plot for Flood Flow Umaisha.

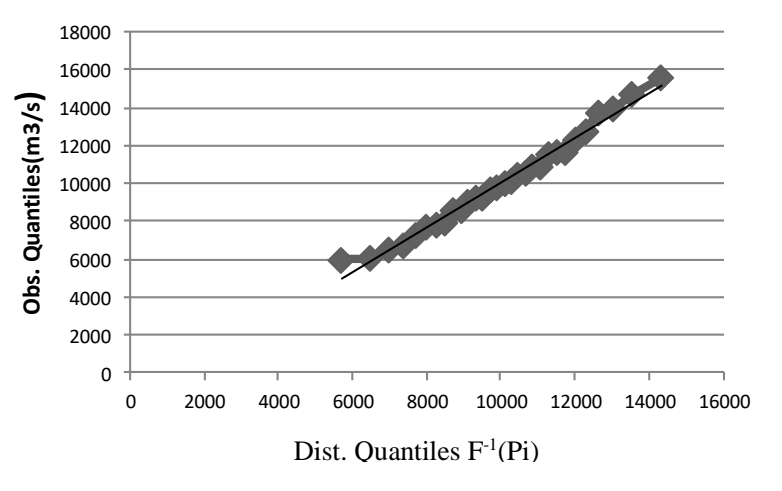

Fig. 9: PR3 Q-Q Plot for Flood Flow Umaisha. 


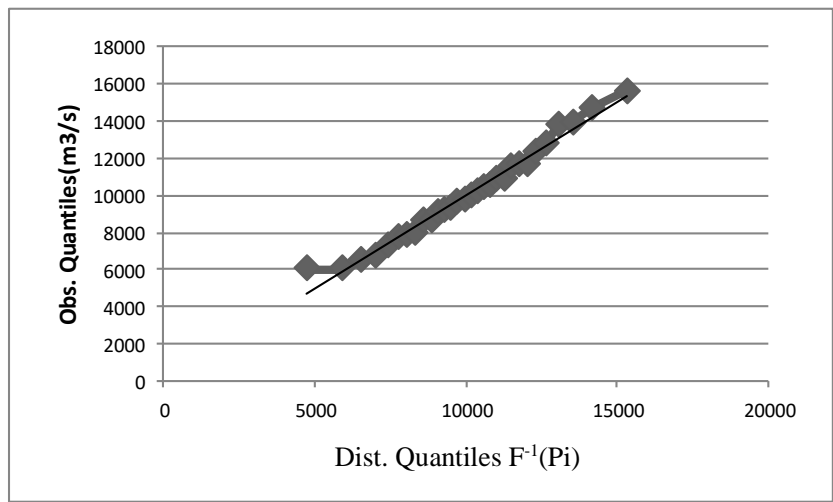

Fig. 10: GEV Q-Q Plot for Flood Flow Umaisha.

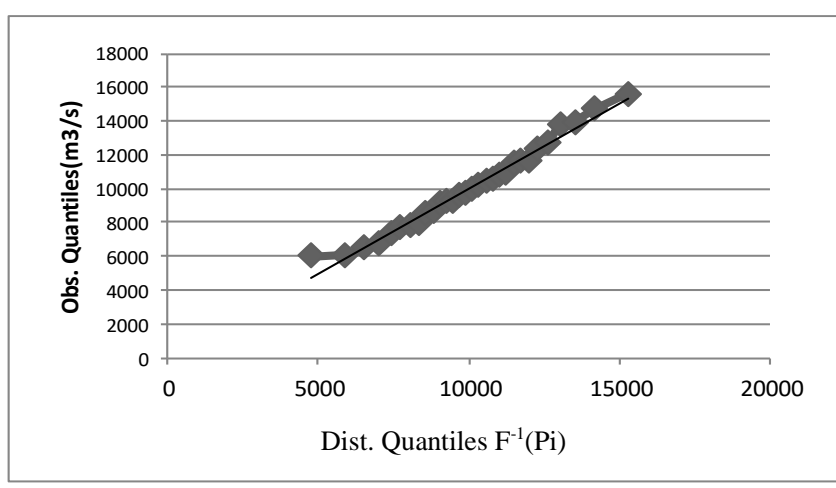

Fig. 11. GEV Q-Q Plot for Flood Flow Umaisha.

\section{B. Summary of Results}

The results of goodness-of-fit tests are presented in Table 4. Similarly, the model performances are ranked on a scale of 1-5, with rank 5 representing the best-fit-distribution for the statistical measures. Consequently, the probability distribution model that has the highest total score is adjudged the best-fit distribution for the study station, and so on. In case of a tie, equal ranks are given to the competing distributions. It may be found from Table 4 that GEV is best-fit distribution for Umaisha, Makurdi, and Yola stations, while PR3 is best-fit distribution at Ibi station. The total scores for each distribution across the stations are graphically displayed in Fig. 12 to 15 . Fig. 16 shows the overall performances with GEV distribution being the optimum distribution, seconded by PR3 and thirdly, LP3.

Table 5 shows the quantile estimates with $95 \%$ confidence interval for the hydrological stations for Benin river basin. It shows the estimated quantiles lying within the computed range of upper and lower confidence limits.

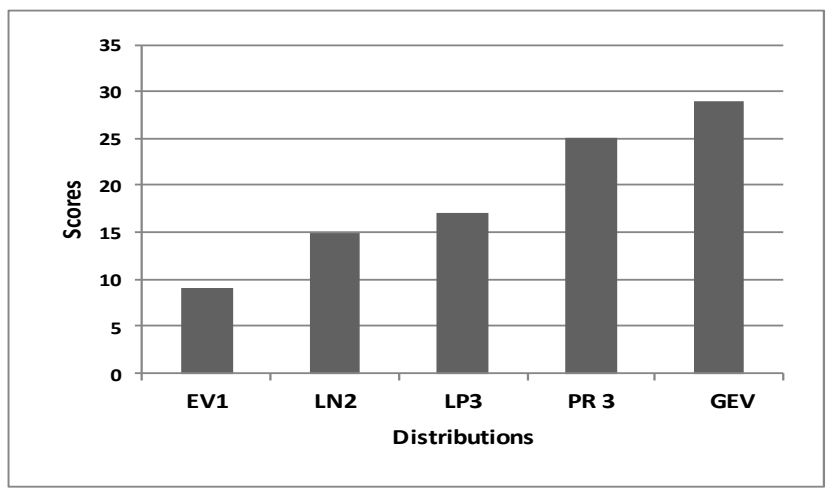

Fig. 12. Goodness - Of- Fit Scores for Umaisha.

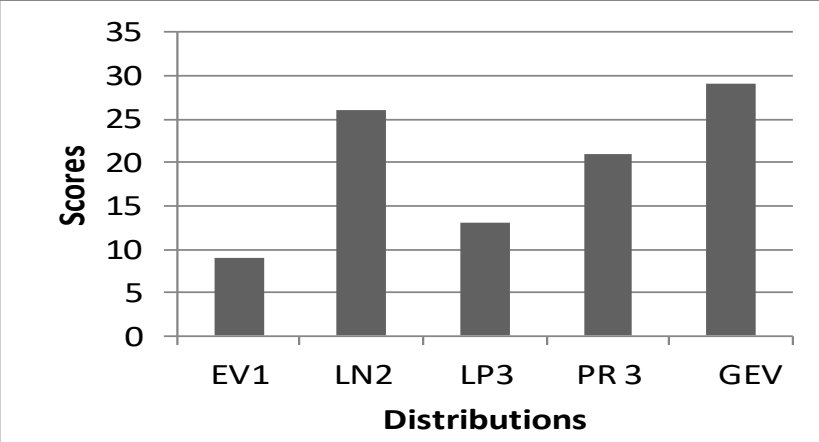

Fig. 13. Goodness - Of- Fit Scores for Makurdi.

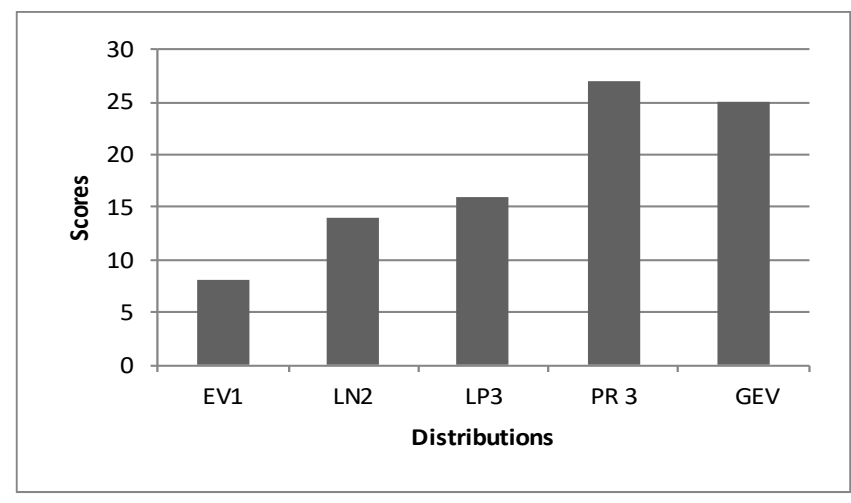

Fig. 14. Goodness - Of- Fit Scores for Ibi

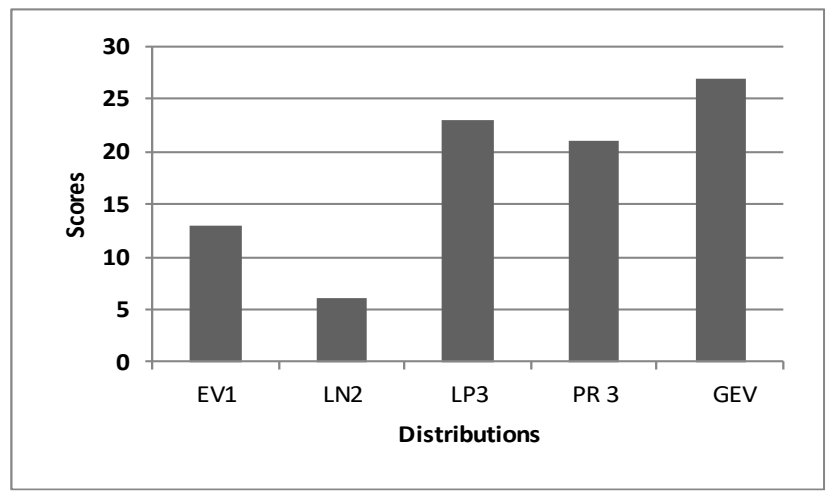

Fig. 15. Goodness - Of- Fit Scores for Yola.

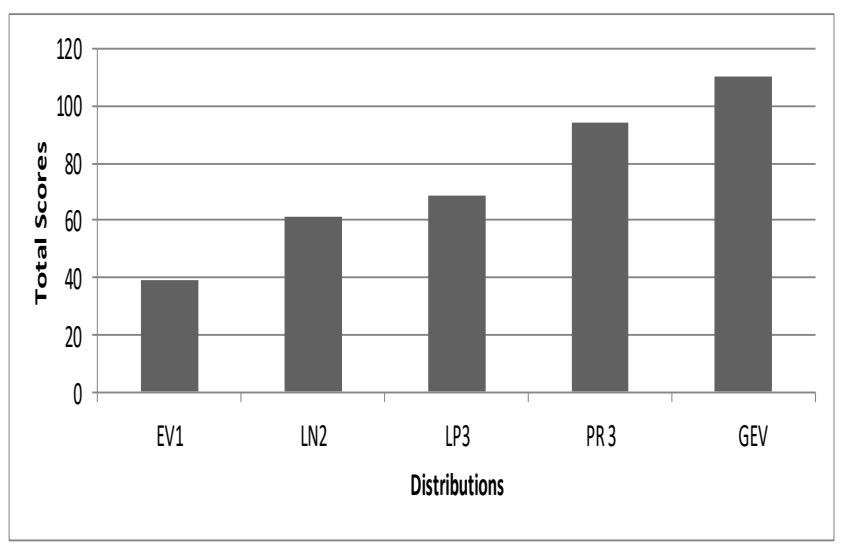

Fig. 16. Goodness - Of- Fit Total Scores for all stations. 
TABLE 4: EvaluATION OF PROBABILITY DisTRIBUTION MODELS

\begin{tabular}{|c|c|c|c|c|c|c|c|c|}
\hline Station & PDF & dmod & NSE & PBIAS & Tot. Accuracy & RSR & RRMSE & Total Score \\
\hline \multirow{5}{*}{ Umaisha } & EV1 & 1 & 2 & 2 & 1 & 1 & 2 & 9 \\
\hline & LN2 & 2 & 3 & 3 & 2 & 2 & 3 & 15 \\
\hline & LP3 & 3 & 3 & 1 & 3 & 3 & 4 & 17 \\
\hline & PR3 & 4 & 4 & 5 & 4 & 4 & 4 & 25 \\
\hline & GEV & 5 & 5 & 4 & 5 & 5 & 5 & 29 \\
\hline \multirow{5}{*}{ Makurdi } & EV1 & 2 & 2 & 2 & 1 & 1 & 1 & 9 \\
\hline & LN2 & 4 & 4 & 4 & 4 & 5 & 5 & 26 \\
\hline & LP3 & 3 & 2 & 1 & 2 & 3 & 2 & 13 \\
\hline & PR3 & 4 & 4 & 3 & 3 & 4 & 3 & 21 \\
\hline & GEV & 5 & 5 & 5 & 5 & 5 & 4 & 29 \\
\hline \multirow{5}{*}{ Ibi } & EV1 & 1 & 1 & 3 & 1 & 1 & 1 & 8 \\
\hline & LN2 & 2 & 2 & 4 & 2 & 2 & 2 & 14 \\
\hline & LP3 & 3 & 3 & 1 & 3 & 3 & 3 & 16 \\
\hline & PR3 & 5 & 5 & 2 & 5 & 5 & 5 & 27 \\
\hline & GEV & 4 & 4 & 5 & 4 & 4 & 4 & 25 \\
\hline \multirow{5}{*}{ Yola } & EV1 & 2 & 2 & 3 & 2 & 2 & 2 & 13 \\
\hline & LN2 & 1 & 1 & 1 & 1 & 1 & 1 & 6 \\
\hline & LP3 & 5 & 3 & 2 & 4 & 4 & 5 & 23 \\
\hline & PR3 & 3 & 4 & 5 & 3 & 3 & 3 & 21 \\
\hline & GEV & 4 & 5 & 4 & 5 & 5 & 4 & 27 \\
\hline
\end{tabular}

TABLE 5: QUANTILE ESTIMATES WITH 95\% CONFIDENCE INTERVAL FOR BENUE RIVER BASIN

\begin{tabular}{|c|c|c|c|c|c|c|c|}
\hline \multirow{3}{*}{ Station } & \multirow{3}{*}{ Distribution } & \multirow{3}{*}{ Statistics } & \multicolumn{5}{|c|}{ Non Exceedance Probability $(\mathrm{F})$ and Return Period $(\mathrm{T})$} \\
\hline & & & 0.90 & 0.95 & 0.95 & 0.98 & 0.99 \\
\hline & & & 10.00 & 20.00 & 25.00 & 50.00 & 100.00 \\
\hline \multirow[t]{9}{*}{ Umaisha } & \multirow[t]{3}{*}{ GEV } & Lower Limit & 12448.74 & 13403.93 & 13685.28 & 14500.99 & 15249.45 \\
\hline & & Q. estimates & 13437.22 & 14526.75 & 14844.95 & 15749.73 & 16545.22 \\
\hline & & Upper Limit & 14632.16 & 15953.84 & 16352.46 & 17526.19 & 18621.42 \\
\hline & \multirow[t]{3}{*}{ PR3 } & Lower Limit & 12375.36 & 13538.01 & 13896.49 & 14978.63 & 16029.55 \\
\hline & & Q. estimates & 13376.54 & 14461.86 & 14785.98 & 15734.29 & 16613.12 \\
\hline & & Upper Limit & 15427.74 & 17462.49 & 18118.67 & 20173.69 & 22267.97 \\
\hline & \multirow[t]{3}{*}{ LP3 } & Lower Limit & 12375.36 & 13538.01 & 13896.49 & 14978.63 & 16029.55 \\
\hline & & Q. estimates & 13592.01 & 15049.40 & 15508.36 & 16917.29 & 18315.36 \\
\hline & & Upper Limit & 15427.74 & 1762.49 & 18118.67 & 20173.69 & 22267.97 \\
\hline \multirow[t]{9}{*}{ Makurdi } & \multirow[t]{3}{*}{ LP3 } & Lower Limit & 11830.11 & 12594.94 & 12824.27 & 13499.32 & 14131.81 \\
\hline & & Q. estimates & 12683.52 & 13616.15 & 13900.93 & 14750.95 & 15561.38 \\
\hline & & Upper Limit & 13932.70 & 15187.03 & 15577.42 & 16760.68 & 17911.65 \\
\hline & \multirow[t]{3}{*}{ PR3 } & Lower Limit & 11949.19 & 12717.24 & 12945.12 & 13609.99 & 14225.39 \\
\hline & & Q. estimates & 12662.67 & 13536.20 & 13799.06 & 14573.17 & 15296.94 \\
\hline & & Upper Limit & 13629.13 & 14693.63 & 15017.22 & 15976.33 & 16879.31 \\
\hline & \multirow[t]{3}{*}{ GEV } & Lower Limit & 11949.19 & 12717.24 & 12945.12 & 13609.99 & 14225.39 \\
\hline & & Q. estimates & 12608.16 & 13582.49 & 13844.69 & 14601.07 & 15280.9 \\
\hline & & Upper Limit & 13629.13 & 14693.63 & 15017.22 & 15976.33 & 16879.31 \\
\hline \multirow[t]{9}{*}{ Ibi } & \multirow[t]{3}{*}{ GEV } & Lower Limit & 10182.23 & 10680.01 & 10815.95 & 11184.38 & 11490.95 \\
\hline & & Q. estimates & 10974.80 & 11448.40 & 11567.58 & 11862.54 & 12071.82 \\
\hline & & Upper Limit & 11929.88 & 12605.10 & 12792.94 & 13308.30 & 13743.24 \\
\hline & \multirow[t]{3}{*}{ PR3 } & Lower Limit & 10182.23 & 10680.01 & 10815.95 & 11184.38 & 11490.95 \\
\hline & & Q. estimates & 10930.84 & 11489.98 & 11644.32 & 12065.60 & 12419.06 \\
\hline & & Upper Limit & 11929.88 & 12605.10 & 12792.94 & 13308.30 & 13743.24 \\
\hline & \multirow[t]{3}{*}{ LP3 } & Lower Limit & 9894.67 & 10208.61 & 10282.03 & 10451.65 & 10558.38 \\
\hline & & Q. estimates & 10955.16 & 11338.08 & 11424.34 & 11637.89 & 11770.42 \\
\hline & & Upper Limit & 12500.00 & 13021.07 & 13144.95 & 13434.06 & 13617.97 \\
\hline \multirow[t]{9}{*}{ Yola } & \multirow[t]{4}{*}{ GEV } & Lower Limit & 4990.86 & 5549.97 & 5715.86 & 6199.84 & 6647.81 \\
\hline & & Q. estimates & 5532.02 & 6125.95 & 6298.30 & 6785.33 & 7209.53 \\
\hline & & Upper Limit & 6213.91 & 6988.82 & 7224.37 & 7922.54 & 8579.84 \\
\hline & & Lower Limit & 4990.86 & 5549.98 & 5715.86 & 6199.84 & 6647.81 \\
\hline & \multirow[t]{3}{*}{ PR3 } & Q. estimates & 5510.30 & 6146.19 & 6337.54 & 6901.04 & 7427.89 \\
\hline & & Upper Limit & 6213.91 & 6988.82 & 7224.37 & 7922.54 & 8579.84 \\
\hline & & Lower Limit & 5029.22 & 5946.08 & 6248.97 & 7223.79 & 8261.09 \\
\hline & \multirow[t]{2}{*}{ LP3 } & Q. estimates & 5876.37 & 7109.51 & 7528.96 & 8913.49 & 10437.38 \\
\hline & & Upper Limit & 7254.29 & 9149.46 & 9818.31 & 12101.94 & 14735.21 \\
\hline
\end{tabular}

\section{Discussion}

The aim of this study is to determine the optimum probability distribution model of flood flow in the Benue River Basin. The selected distributions; EV1, LN2, LP3, PR3 and GEV were evaluated against the following goodness - of - fit tests: Dmod, RRMSE, NSE, PBIAS, and RSR, in order to reveal the optimum distribution model. The discussion is presented in the following order:

1. Comparison with previous studies in Nigeria: The hydrological stations investigated have not been studied previously, therefore, there are no previous findings with which to compare with the results obtained. Previous studies worthy of discussion in the Benue River Basin are [21], who evaluated three probability distribution models; EV1, LN2 and LP3 and found LN2 and LP3, the best-fit models. In contrast, the present study used EV1, LN2, LP3, PR3 and GEV distributions and found the best - fit distributions in the following order: GEV, PR3 and LP3.

2. Suitability of Selected Distributions: The best-fit distributions found in this study are GEV, PR3 and LP3 distributions. The choice of GEV distribution agrees with Haktanir [50] who reported that GEV has a convincing 
relevance to the peak of floods, as most other probability distributions are not true depictions of flood peaks from the theoretical cause - effect standpoint. The GEV distribution is used as standard probability distribution model in 1 country, PR3 in 7 countries and LP3 also in 7 countries Cunnane [18].

\section{SUMMARY AND CONCLUSION}

The goal of this study is to evaluate the AMS of four gauging stations of Benue River in the Benue River Basin. The flood frequency analysis was performed using five probability distribution models: EV1, LN2, LP3, PR3 and GEV. The best-fit distribution is identified at each gauging station based on the highest total rank score for all the tests. A total of five goodness-of-fit tests are adopted: Dmod, RRMSE, NSE, PBIAS, and RSR to identify the best-fit probability distribution model with MoM for parameter estimation. The Study revealed GEV distribution the best-fit distribution for Umaisha, Makurdi, and Yola stations while PR3 is best at Ibi station. The overall assessment (Fig. 16) shows that GEV is the best-fit distribution, seconded by PR3 and thirdly, LP3. The study recommends the development of a regional GEV, PR3 and LP3 distributions using the existing hydrological map of Nigeria which had demarcated the country into eight hydrological homogeneous regions.

\section{REFERENCES}

[1] FFE, Vol. II, OPW, 2014: Flood Frequency Estimation, Office of Public Works, 2014.

[2] He, J., Anderson, A. and Valeo, C. (2015), Bias compensation in flood frequency analysis, Hydrological Sciences Journal, 60(13),381-392. http://dx.doi.org/10.1080/02626667.2014.885651.

[3] EM 1110-2-1450(1994). HYDROLOGIC FREQUENCY ESTIMATES, U.S. Army Corps of Engineers, Washington, DC 20314-1000.

[4] Khaliq, M.N., Ouarda, T.B.M.J., Ondo, J.-C., Gachon, P., and Bobee, B. (2006). Frequency analysis of a sequence of dependent and/or non-stationary hydro - meteorological observations: A review, Journal of Hydrology, 329, pp.534 - 552.

[5] WMO168_Ed2009_Vol._II_Ch5_Up2008_en, Chapter 5: Extreme Value Analysis.

[6] Onoz, B. and Bayazit, M. (1995), Best-fit distributions largest available flood samples, Journal of Hydrology, 167 (1995), 195 208.

[7] Chen, X., Shao, Q., Xu, C-Yu., Zhang, J., Zhang, L., and Ye, C. (2017). Comparative Study on the Selection Criteria for Fitting Flood Frequency Distribution Models with Emphasis on Upper Tail Behavoiur, water 2017, 9, 320; doi:10.3390/w9050320.

[8] Vogel, R.M. and Wilson, I. (1996). Probability Distribution of Annual, Maximum, Mean, and Minimum Streamflows in the United States. Journal of Hydrologic Engineering, Vol.1, No. 2, pp. $69-$ 76.

[9] Laio, F., Di Baldassarre, G., and Montanari, A., (2009), Model selection techniques for the frequency analysis of hydrological extremes, Water Resources Research, VOL. 45, W07416, doi:10.1029/2007WR006666, 2009.

[10] Ahmad, I., Faward, M. and Mahmood, I. (2015). At -Site Flood Frequency Analysis of Annual Maximum Stream Flows in Pakistan Using Robust Estimation Methods. Pol. J. Environ. Stud. Vol. 24, No.6 (2015), pp. 2345 - 2353. DOI: 10. 15244/pjoes/59585.

[11] Rahman A.S, Rahman, A. Zaman M.A., Haddad K., Ahsan A., Imteaz M. (2013), A study on selection of probability distributions for at - site flood frequency analysis in Australia, Nat Hazards (2013) 69:1803 -1813. DOI 10.1007/s11069-013-0775-y.

[12] Morlot, M, Brilly, M. and Sraj, M (2019). Characterisation of the floods in the Danude River Basin through Flood Frequency and
Seasonality Analysis. Acta hydrotecnica 32/57 (2019), pp. 73 - 89, http://doi.org/10.15292/acta.hydro.2019.06.

[13] Strupczewski, W.G., Kochanck, K., and Bogdanowicz, E. (2014) Flood frequency analysis supported by the largest historical flood. Nat.Hazards Earth Syst. Sci., 14, 1543 - 1551, doi:10.5194/nhess14-1543-2014.

[14] Prieto, C., Patel, D., and Han, D. (2020). Preface: Advances in flood risk assessment and management. Natural Hazards and Earth System Sciences, 20 (4), 1045 - 1048. http://doi:org/10.5194/nhess20-1045- 2020

[15] Kousar S, Khan AR, Ul Hassan M, Noreen Z, Bhatti SH. Some bestfit probability distributions for at-site flood frequencyanalysis of the Ume River. J Flood RiskManagement.2020; 13: e12640. https://doi.org/10.1111/jfr3.12640

[16] UI Hassan, M, Hayat, O. and Noreen, Z (2019). Selecting the best probability for at - flood frequency analysis; a study of Torne River SN Applied Sciences (2019) 1: 1629: http://doi.org/10.10.1007/s42452-019-1584-z.

[17] Philip Kibet Langat 1, Lalit Kumar 1 and Richard Koech 2 (2019). Identification of the Most Suitable Probability Distribution Models for Maximum, Minimum, and Mean Streamflow. Water 2019, 11, 734; doi: 10.3390/w11040734

[18] Cunnane, C., (1989). Statistical Distribution for Flood Frequency Analysis. Operational Hydrol. Rep. 33, World Meteorological Organisation, Geneva.

[19] FLOODFREQcost Action ES0901, Review of Applied-Statistical Methods for Flood - Frequency Analysis in Europe (WG2).

[20] Abida H. and Ellouze M (2007), Probability distribution of flood flows in Tunisia, Hydrol. Earth Syst. Sci. Discuss., 4, 957 - 981.

[21] Izinyon, O.C., and Ajumuka, H.N., (2013). Probability distribution models for flood prediction in Upper Benue River Basin- Part II. Civil and Environmental Research, Vol. 3, No.2, pp.62 - 74

[22] Rao A.A and Hamed K.H (2000), Flood Frequency Analysis, CRC Press, ISBN 0-412-55280-9.

[23] Van Gelder, P.H.A.J.M. Wang, W., and Vrijling, J.K. (2007). Statistical Estimation Methods for Extreme Hydrological Events in Vasiliev, O.F et al. (eds.) Extreme Hydrological Events: New Concepts for Security, 199-252. 2007 Springer.

[24] Hansen, C. (2011). Frequency Analysis of Annual Maximum Rainfall for Selected Sites in Alberta, Using At - Site and Regional Approaches. Edmonton, Alberta.

[25] AMEC Environmental \& Infrastructure (2014). Frequency Analysis Procedures for Stormwater Design Manual, CW2138.

[26] Kite, G. W. (1977). Frequency and risk analyses in hydrology. WaterResources Publications, https://books.google.se/books?id=WZt-AAAAIAAJ.

[27] Sankarasubramanian A. \& Srinivasan K. Investigation and comparison of sampling properties of L-moments and conventional moments. J Hydrol 1999, 218, (1-2), 13-34.

[28] Bezak, N., Brilly, M., and Sraj, M. (2014). Flood frequency analysis, statistical trends and seasonality analysis of discharge data: a case study of the Litija station on the Sava River. Journal of Flood Risk Management, 9 (2016) $154-168$

[29] Son, K., Lin, L., Band, L., and Owens, E.M. (2019). Modelling the interaction of climate, forest ecosystem, and hydrology to estimate catchment dissolved organic carbon export. Hydrological processes. 2019; 33:1448-1464.https://doi.org/10.1002/hyp.13412

[30] Moriasi, D.N., Gitau, M.W., Pai, N., and Daggupati. P. (2015). Hydrologic and Water Quality Models: Performance Measures and Evaluation Criteria. Transactions of the American Society of Agricultural and Biological Engineers, Vol. 58(6): 1763- 1785.

[31] Janssen, P. H. M. and Heuberger, P. S. C: Calibration of processoriented models, Ecological Modelling, 83, 55-66, 1995.

[32] Bennett, N. D., Croke, B. F. W., Guariso, G., Guillaume, J. H. A.,Hamilton, S. H., Jakeman, A. J., Marsili-Libelli, S., Newham, L.T. H., Norton, J. P., Perrin, C., Pierce, S. A., Robson, B.,Seppelt, R., Voinov, A. A., Fath, B. D., \& Andreassian, V. (2013) Characterising performance of environmental models.Environ Model $\quad$ Software, $\quad 40, \quad 1-20$ http://dx.doi.org/10.1016/j.envsoft.2012.09.011.

[33] Bilau A. A, Witt E, Lill I, Bustani S.A(2012), Housing Reconstruction Following the 2012 Nigerian Floods: Was it Built Back Better? in Prins, M., Wamelink, H., Giddings, B., Ku,K., and Feenstra, M.(Eds.)(2016).Proceeding of the CIB World Building Congress 2016: Volume II-Environmental opportunities; Constructing Commitment and Acknowledging Human Experiences. (Tampere University of Technology. Department of Civil Engineering. Construction Management and economics. Report; Vol. 18). Tampere University of Technology. 
[34] Di Baldassarre G; Montanari A; Lins H; Koutsoyiannis D; Brandimarte L; Bloschl G (2010). Flood Fatalities in Africa: From diagnosis to mitigation, Geophysical Research letters, 37, L22402, doi:10.1029/2010GL045467, 2010.

[35] Naghettini, M (ed). Fundamentals of Statistical Hydrology, ISBN $978-3-319-43561-9$, Springer.

[36] Krause, P., Boyle, D.P., and Base, F. (2005). Comparison of different efficiency criteria for hydrological model assessment, advances in Geosciences, 5, pp.89-97.

[37] Willmott, C.J., Robeson, S.M. and Matsuura, K. (2012). Short Communication: A refined index of model -performance. Int. J. Climatol. 32: 2088 - 2094(2012)

[38] Tao, D.Q., Nguyen, V-T-V and Bourque, A. (2002). On selection of probability distributions for representing extreme precipitation in southern Quebec. Annual Conference of the Canadian Society for Civil Engineering.

[39] Gupta, H.V., Sorooshian, S, and Yapo, P.O. (1999). Status of automatic calibration for hydrologic models: Comparison with multilevel calibration. J. hydrologic Eng. 4(2): 135 - 143.

[40] Pandit, R.K. and Infield, D. (2018) Q-Q plot for assessment of Gaussian Process wind turbine power curve error distribution function. $9^{\text {th }}$ European Workshop on Structural Health Monitoring, July 10 - 13, 2018, Manchester, United Kingdom.

[41] Cunnane, C. (1978), Unbiased Plotting Positions - A Review, Journal of Hydrology,37(1978) 205-222

[42] In-Na, N. and Ngugen, V.-T.-V. (1989). An Unbiased Plotting Position Formula for the General Extreme Value Distribution. Journal of hydrology, 106(1989), pp.193 - 209.

[43] WMO: No.718, 1989 (World Meteorological Organization). (1989). Statistical distributions for flood frequency analysis. Geneva: World Meteorological Organization.

[44] Stedinger, J.R., Vogel, R.M. and Foufoula-Georgiou, E., 1993. Frequency analysis of extreme events. Handbook of Hydrology, New York, USA

[45] Naghavi, B. and Yu Xin, F. (1996). Selection of ParameterEstimation Method for LP3 Distribution. Journal of Irrigation and Drainage Engineering, Vol. 122, No. pp.24 - 30.

[46] Wilson, E.B. and Hilferty, M.M. (1931). "The distribution of Chisqure", Proceedings. National Academic of Science (New York), 17(12): 684- 688 .

[47] Abramawitz, M. and Stegun, I. A. (1965). Handbook of Mathematical Functions. Dover Publications, New York.

[48] Golitzen, K. G. (eds)., Inger, A., Dione, O., Jaroewich-Holder, M., Olivry, J-C. (2005). The Niger River Basin: A vision for Sustainable Management. DOI: 10. 1596/978-0-8213-6203-7., ISBN-10: 08213-6203-8.

[49] ASCE. 1993. Criteria for evaluation of watershed models. J. Irrigation Drainage Eng.119(3): 429-442.

[50] Haktanir, T., (1992). Comparison of various flood frequency distributions using annual flood peaks data of rivers in Anatolia, Journal of Hydrology, 136(1992), 1-31.

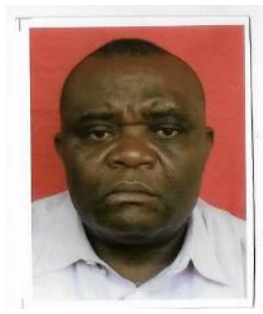

Dr. Ologhadien is an Associate Professor and formerly Acting Head, Department of Marine Engineering at the Rivers State University of Science and Technology, Port Harcourt. He graduated in 1988 with Bachelor of Technology (B. Tech) degree in Civil Engineering from the Rivers State University of Science and Technology, Port Harcourt, Nigeria. He received his M. Eng and PhD degrees in 2003 and 2012, respectively in Civil Engineering from University of Port Harcourt, Nigeria. He also received a PGD in Hydraulic Engineering from IHE, Delft, Netherlands in 1991. He has over 25 years of teaching, research and consultancy experience in Hydraulic engineering, Water resources Engineering, River and Coastal engineering. Dr. Ologhadien has authored several publications in peer- review journals and over 100 technical reports to his credit.

Dr. Ologhadien is professional engineer registered with the Council for the Regulation of Engineering in Nigeria (COREN - R9516), a corporate member of the Nigerian Society of Engineers (R07389) and the International Association of Hydraulic Research (I - 7512). He is also a recipient of two fellowships from the Netherlands Government in 1991 and 2003, respectively. 